\title{
Late onset of cerebellar cortical degeneration in a Magellanic penguin (Spheniscus magellanicus)
}

\author{
Marianthi IOANNIDIS ${ }^{1) \#, ~ M i y u u ~ T A N A K A ~}{ }^{1) \#, ~ S a y a k a ~ Y A S U I ~}{ }^{1)}$, Chiho KEZUKA ${ }^{2)}$, \\ Maremichi OYAMADA ${ }^{3)}$, Tetsuya HASEGAWA ${ }^{3)}$, Takeshi IZAWA ${ }^{1)}$, Jyoji YAMATE ${ }^{1)}$ \\ and Mitsuru KUWAMURA ${ }^{1 \text { )* }}$ \\ 1)Laboratory of Veterinary Pathology, Graduate School of Life and Environmental Science, Osaka Prefecture \\ University, Izumisano, Osaka 598-8531, Japan \\ ${ }^{2)}$ Kobe Municipal Suma Aqualife Park, Kobe, Hyogo 654-0049, Japan \\ ${ }^{3)}$ Kakogawa Animal Hospital, Kakogawa, Hyogo 675-0055, Japan
}

J. Vet. Med. Sci.

81(5): 750-752, 2019

doi: 10.1292/jvms.19-0089

Received: 12 February 2019

Accepted: 8 March 2019

Published online in J-STAGE:

5 April 2019
ABSTRACT. An 8-year-old female Magellanic penguin (Spheniscus magellanicus) started to show epilepsy-like seizures. Subsequent magnetic resonance imaging (MRI) examinations did not reveal any responsible lesions. The neurological symptoms worsened at the age of 10 . This penguin became recumbent and died 6 months later after the apparition of the recumbency. At necropsy, only multiple yellowish necrotic lesions in the air sacs and lungs were found. Histopathological evaluation of the brain showed a marked loss of Purkinje cells and many hypertrophied parvalbumin-positive basket/stellate cells were seen in the cerebellar cortex. Calbindin immunohistochemistry demonstrated disrupted arrangement of dendrites in the Purkinje cells. This case was diagnosed as cerebellar cortical degeneration with a very late onset and a slow progression in a Magellanic penguin.

KEY WORDS: bird, cerebellar abiotrophy, immunohistochemistry, Magellanic penguin, neurodegeneration

Many cases with cerebellar cortical degeneration (CCD) have been reported in animals. Cerebellar abiotrophy refers to premature or accelerated degeneration of fully-developed neurons, presumably caused by intrinsic metabolic defects in veterinary medicine [4]. Cerebellar abiotrophy was described for the first time in cattle in 1951 [8, 14]. The diagnosis is usually based on a post-mortem histopathological examination of the cerebellum. This disease has been reported in many species; mostly in dogs $[1,5,7,14]$ and horses [3, 13], but also in lamas [12], cats [2, 15], cattle, goats [9] and koala [10]. In some species, an autosomal recessive mode of inheritance was established as in Arabian horses with a missense mutation of MUTYH [13] or SNX14 in the Hungarian Vizsla dog [5]. Early and late onset with slow progression ranging from a few weeks to several years of age were both described. Early onset occurs in young animals which are healthy at birth and progressively develop cerebellar troubles, and late onset in adult specimens with a generally slower progression. In dogs, intermediate onset is also described [1].

CCD can be manifested by different kinds of cerebellar degeneration, but Purkinje neurons degeneration and depletion are most frequently reported. There may be secondary granule cells loss, reactive gliosis, and Wallerian type degeneration [4, 12], although primary granule cells degenerations are also reported [4]. Until now and to the best of our knowledge, this cerebellar disease has mostly been described by clinical cases in domestic species but not in birds. In the present case report, we report histopathological and immunohistochemical features on a Magellanic penguin (Spheniscus magellanicus) diagnosed as a late-onset of CCD.

An 8-year-old female Magellanic penguin started to show frequent episodes of tonic attack in June 2014. Magnetic resonance imaging (MRI) of the brain was performed and the assessment revealed no abnormality. The penguin was treated with zonisamide in combination with phenobarbital antiepileptic drugs and became clinically healthy. Two years after the initial examination, the penguin started to show signs of staggering when walking. In June 2016, the animal started to show gait abnormality and nystagmus, and became recumbent. In September 2016, the penguin started to vomit frequently and died 6 months later after the apparition of the recumbency. Post-mortem MRI revealed that the amounts of cerebrospinal fluid in the 4th ventricle and within the cerebellar folia were increased compared to the previous MRI carried out 2 years prior. CCD was suspected by the thinner cerebellar folia and wider sulci. At necropsy, there was no macroscopic evidence of brain degeneration and additional lesions

*Correspondence to: Kuwamura, M.: kuwamura@vet.osakafu-u.ac.jp \#These authors contributed equally to this work.

(c2019 The Japanese Society of Veterinary Science

This is an open-access article distributed under the terms of the Creative Commons Attribution Non-Commercial No Derivatives (by-nc-nd) License. (CC-BY-NC-ND 4.0: https://creativecommons.org/licenses/by-nc-nd/4.0/) 


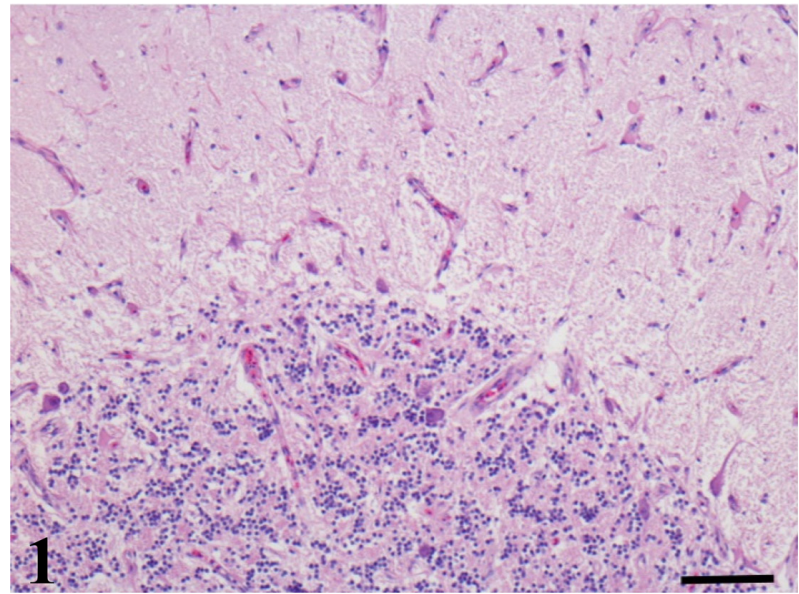

Fig. 1. The cerebellar cortex shows marked loss of normal Purkinje neurons. Prominent neovascularization is also noted in the affected molecular layers. HE. Bar $=100 \mu \mathrm{m}$.

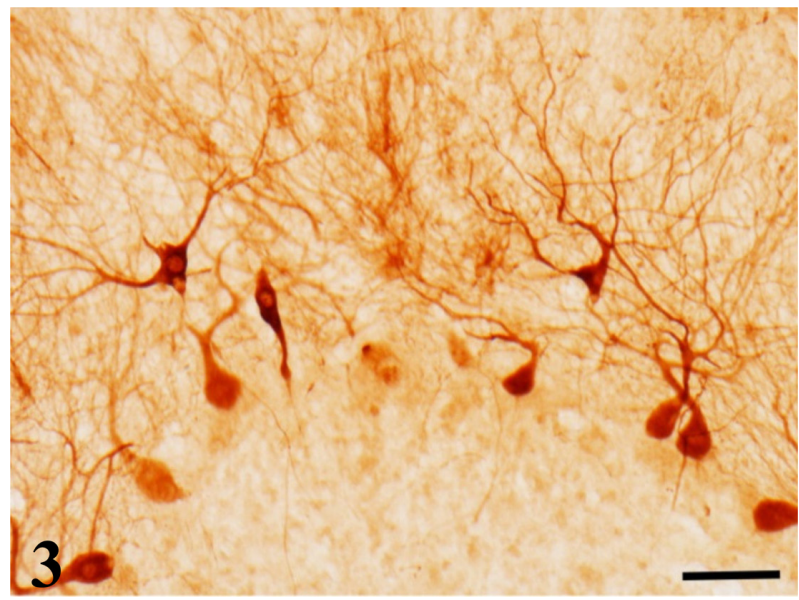

Fig. 3. Calbindin immunoreactivity in the molecular layer of the cerebellar cortex. Dislocated and irregular Purkinje cells are observed. Bar $=100 \mu \mathrm{m}$.

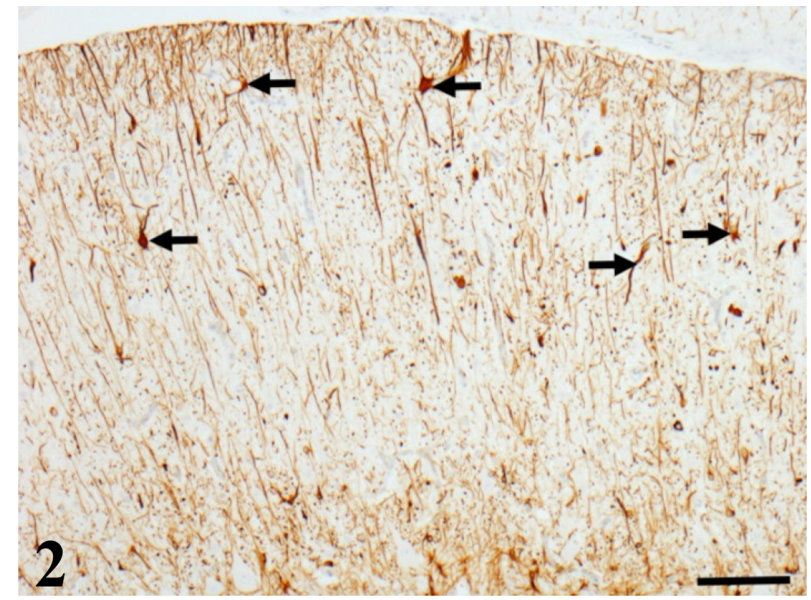

Fig. 2. Immunohistochemistry for GFAP. Gliosis and plumped astrocytes (arrows) are observed in the molecular layer. $\mathrm{Bar}=100 \mu \mathrm{m}$.

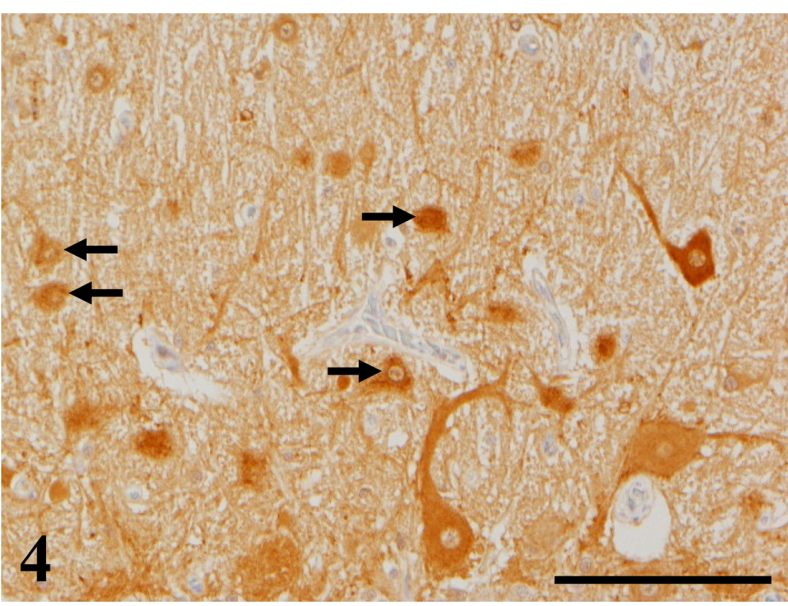

Fig. 4. Parvalbumin immunoreactivity in the molecular layer showing hypertrophied basket cells (arrows). Bar $=100 \mu \mathrm{m}$.

as yellowish multiple necrotic nodules in the air sacs and lungs were seen. The following organs were sampled: liver, spleen, kidneys, heart, lungs, stomach, pancreas, ovary, cerebrum, and cerebellum. Collected samples were fixed in 10\% neutral-buffered formalin and embedded in paraffin. Histologic sections were cut at $4 \mu \mathrm{m}$ and stained with routinely hematoxylin and eosin (HE). Sections from lungs were stained by periodic acid-Schiff (PAS) reaction. Immunohistochemistry was also performed on additional coronal and sagittal sections through folia of the cerebellum. Paraffin-embedded tissue sections were dewaxed and pretreated in a microwave with $0.01 \mathrm{M}$ citrate buffer ( $\mathrm{pH}$ 6.0) for $20 \mathrm{~min}$. Sections were then incubated for $1 \mathrm{hr}$ at room temperature with the following antibodies: mouse anti-glial fibrillary acid protein (GFAP) (clone GA5, 1:1,500; Cell signalling, Denvers, MA, U.S.A.), mouse anti-parvalbumin (clone PARV-19, 1:200; Sigma-Aldrich, St. Louis, MO, U.S.A.). Horseradish peroxidase-conjugated polymer (Histofine Simple Stain MAX PO; Nichirei, Tokyo, Japan) was used as a secondary antibody. Signals were visualized with 3,3'-diaminobenzidine (DAB Substrate Kit; Nichirei). For the morphology of Purkinje cells, 50- $\mu$ m-thick sections were cut from formalin-fixed cerebellum using a vibratome (Technical Products International, St. Louis, MO. U.S.A.). These sections were stained with rabbit anti-calbindin (clone D1I4Q, 1:200, Cell Signaling) antibody [6, 11] and immunoreactivity was visualized by DAB as chromogen.

Histopathological examinations of cerebellum revealed marked loss of Purkinje cells (Fig. 1). Many hypertrophied neurons and occasional axonal spheroids were found in the molecular layer of the cerebellum. Diffuse fibrillary gliosis, many plump astrocytes, and prominent neovascularization were also noted in the affected molecular layers. In addition to the proliferation of Bergmann glia, bizarrely hypertrophic astrocytes were demonstrable by GFAP immunohistochemistry (Fig. 2). Calbindin immunohistochemistry demonstrated disrupted arrangement of dendrites in the remaining Purkinje cells (Fig. 3). Dislocated 
calbindin-positive Purkinje cells were frequently observed in the deep molecular layer. Parvalbumin immunohistochemistry showed hypertrophied basket/stellate cells closely contacted to the dendrites of Purkinje cells (Fig. 4). Necrotic nodules in the lungs consisted of suppurative necrotizing granulomas; PAS reaction clearly demonstrated a lot of Aspergillus-like fungi in the lesions.

In this report, we presented clinical and pathological findings in relation with a cerebellar disease in this bird. The penguin started neurological abnormality at 8 years old and showed slowly progressive cerebellar disorders with a 6-month history of stagger and recumbency. The most characteristic pathological findings were the loss and dendritic degeneration of cerebellar Purkinje cells. Therefore, we diagnosed this penguin case as CCD. The precise etiology of the present case remains uncertain. In several cases of $\mathrm{CCD}$, an autosomal recessive mode of inheritance is suspected, and genetic bases have been established in specific dog breeds like the Hungarian Viszla dog concerning the mutation of SNX14 [5]. Variation in MUTYH expression might be implicated in the Arabian horse breed [13]. To the best of our knowledge, no CCD case has been reported in birds. Veterinarians should consider the CCD or cerebellar abiotrophy which is related to intrinsic basis, even in animals except the mammalians.

\section{REFERENCES}

1. Bertalan, A., Glass, E. N., Kent, M., De LaHunta, A. and Bradley, C. 2014. Late-onset cerebellar abiotrophy in a Labrador Retriever. Aust. Vet. J. 92: 339-342. [Medline] [CrossRef]

2. Biolatti, C., Gianella, P., Capucchio, M. T., Borrelli, A. and D'Angelo, A. 2010. Late onset and rapid progression of cerebellar abiotrophy in a domestic shorthair cat. J. Small Anim. Pract. 51: 123-126. [Medline] [CrossRef]

3. Blanco, A., Moyano, R., Vivo, J., Flores-Acuña, R., Molina, A., Blanco, C. and Monterde, J. G. 2006. Purkinje cell apoptosis in arabian horses with cerebellar abiotrophy. J. Vet. Med. A Physiol. Pathol. Clin. Med. 53: 286-287. [Medline] [CrossRef]

4. Cantile, C. and Youssef, S. 2016. Nervous system. pp. 318-320. In: Jubb, Kennedy \& Palmer's Pathology of Domestic Animals: Volume 1, 6th ed. (Grant, M. ed.), Elsevier, St. Louis.

5. Fenn, J., Boursnell, M., Hitti, R. J., Jenkins, C. A., Terry, R. L., Priestnall, S. L., Kenny, P. J., Mellersh, C. S. and Forman, O. P. 2016. Genome sequencing reveals a splice donor site mutation in the SNX14 gene associated with a novel cerebellar cortical degeneration in the Hungarian Vizsla dog breed. BMC Genet. 17: 123. [Medline] [CrossRef]

6. Flace, P., Lorusso, L., Laiso, G., Rizzi, A., Cagiano, R., Nico, B., Ribatti, D., Ambrosi, G. and Benagiano, V. 2014. Calbindin-D28K immunoreactivity in the human cerebellar cortex. Anat. Rec. (Hoboken) 297: 1306-1315. [Medline] [CrossRef]

7. Gumber, S., Cho, D. Y. and Morgan, T. W. 2010. Late onset of cerebellar abiotrophy in a boxer dog. Vet. Med. Int. 2010: 406275. [Medline] [CrossRef]

8. Jennings, A. R. and Sumner, G. R. 1951. Cortical cerebellar disease in an Ayrshire calf. Vet. Rec. 63: 60-61. [Medline] [CrossRef]

9. Koehler, J. W., Newcomer, B. W., Holland, M. and Caldwell, J. M. 2015. A novel inherited cerebellar abiotrophy in a cohort of related goats. $J$. Comp. Pathol. 153: 135-139. [Medline] [CrossRef]

10. Kuwamura, M., Murai, F., Nishioka, S., Aoki, M., Ohashi, F., Yamate, J., Kotani, T. and Summers, B. A. 2009. Late onset cerebellar cortical degeneration in a koala. Aust. Vet. J. 87: 342-344. [Medline] [CrossRef]

11. Maskey, D., Pradhan, J., Kim, H. J., Park, K. S., Ahn, S. C. and Kim, M. J. 2010. Immunohistochemical localization of calbindin D28-k, parvalbumin, and calretinin in the cerebellar cortex of the circling mouse. Neurosci. Lett. 483: 132-136. [Medline] [CrossRef]

12. Mouser, P., Lévy, M., Sojka, J. E. and Ramos-Vara, J. A. 2009. Cerebellar abiotrophy in an alpaca (Lama pacos). Vet. Pathol. 46: $1133-1137$. [Medline] [CrossRef]

13. Scott, E. Y., Woolard, K. D., Finno, C. J., Penedo, M. C. T. and Murray, J. D. 2018. Variation in MUTYH expression in Arabian horses with cerebellar abiotrophy. Brain Res. 1678: 330-336. [Medline] [CrossRef]

14. Scott, E. Y., Woolard, K. D., Finno, C. J. and Murray, J. D. 2018. Cerebellar abiotrophy across domestic species. Cerebellum 17: $372-379$. [Medline] [CrossRef]

15. Shamir, M., Perl, S. and Sharon, L. 1999. Late onset of cerebellar abiotrophy in a Siamese cat. J. Small Anim. Pract. 40: 343-345. [Medline] [CrossRef] 